\title{
Selectivity in Small Molecule Splicing Modulation
}

Deepak Kumar, ${ }^{\dagger, " ~ M a n o j ~ K . ~ K a s h y a p, ~}{ }^{\dagger, " ~ J a m e s ~ J . ~ L a ~ C l a i r, ~}{ }^{\ddagger}$ Reymundo Villa, ${ }^{\ddagger}$ Ide Spaanderman ${ }^{\dagger}$, Stephen Chien, ${ }^{\dagger}$ Laura Z. Rassenti, ${ }^{\dagger, \S}$ Thomas J. Kipps, ${ }^{\dagger}{ }^{\S}$ Michael D. Burkart, ${ }^{\ddagger}{ }^{*}$ and Januario E. Castro $^{\dagger, \$, *}$

${ }^{\dagger}$ Moores Cancer Center, University of California San Diego, La Jolla, CA 92093

${ }^{\ddagger}$ Department of Chemistry and Biochemistry, University of California, San Diego, La Jolla, CA 920930358, and

${ }^{\S}$ CLL Research Consortium, and Department of Medicine, University of California, San Diego, La Jolla, CA 92093-0358.

" These authors contributed equally to this work.

*Correspondence: Michael D. Burkart, Phone: 858-534-5673, e-mail: mburkart@ucsd.edu or Januario E. Castro, Phone: 858-822-6386, e-mail: jecastro@ucsd.edu 
Table of Contents

$\begin{array}{ll}\text { Supplementary Figure S1 S2 } & \text { S1 }\end{array}$

$\begin{array}{ll}\text { Supplementary Figure S2 S3 } & \text { S2 }\end{array}$

Supplementary Figure S3 S4

Supplementary Figure S4 S5

$\begin{array}{ll}\text { Supplementary Table S1 } & \text { S6-S7 }\end{array}$

$\begin{array}{ll}\text { Supplementary Table S2 S8 } & \text { S2 }\end{array}$

$\begin{array}{ll}\text { Supplementary Table S3 S9 } & \end{array}$ 


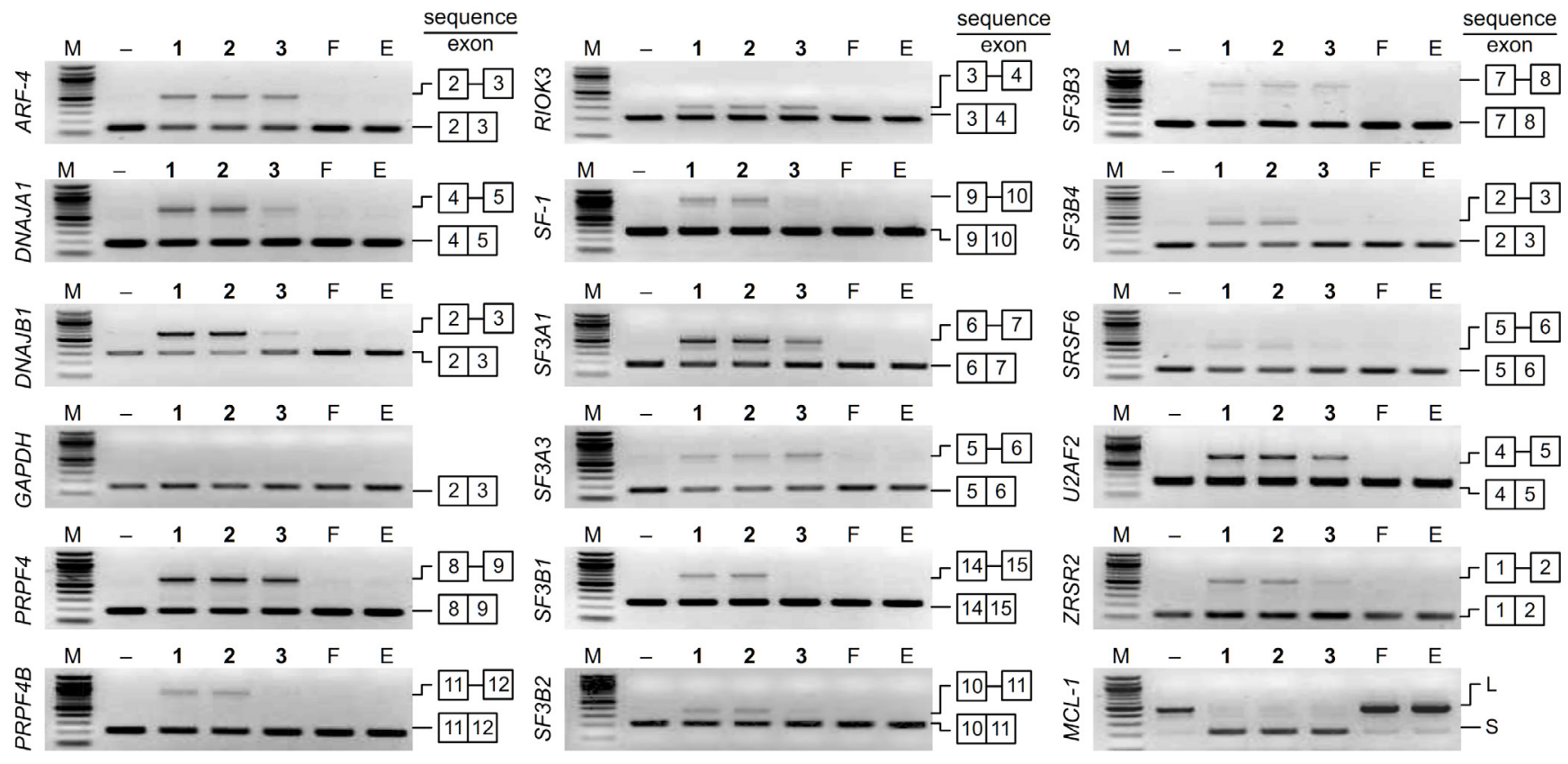

Supplementary Figure S1. RT-PCR analyses of selected genes derived from RNAseq data. MCL-B

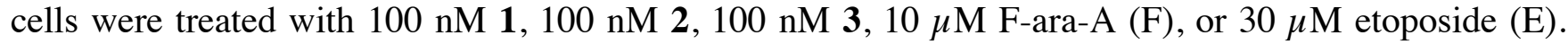
After treatment for $4 \mathrm{~h}$, the levels of spliced and unspliced gene expression were evaluated by RT-PCR analysis. IR was not observed in control (-) and samples treated with F or E, even at supra-physiological concentrations. All PCR reactions depicted in this figure were carried out in the same set of cDNA samples derived after respective treatments. Data from parallel qRT-PCR data can be found in Figure 4. While all genes depicted were evaluated in the same set of cDNA sample after respective treatments. 


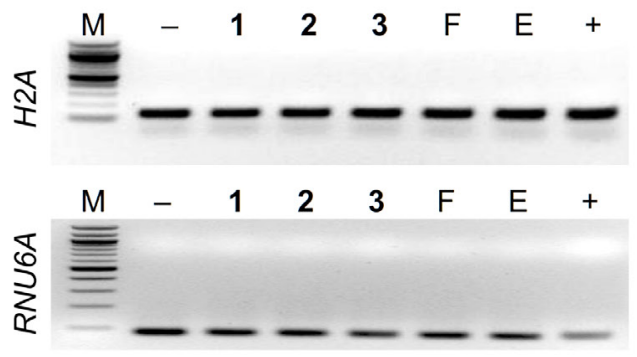

Supplementary Figure S2. RNA isolation and loading controls were conducted using RNU6A and H2A. MCL-B cells were treated with either $100 \mathrm{nM} \mathrm{1,} 100 \mathrm{nM}$ 2,100 nM 3, 10 $\mu \mathrm{M}$ F-ara-A $(\mathrm{F})$, or $30 \mu \mathrm{M}$ of etoposide $(\mathrm{E})$. After treatment for $4 \mathrm{~h}$, the levels of spliced versus unspliced transcripts were evaluated by RT-PCR analysis. IR was not observed in neither the treated cells nor in untreated consider as control (-) or samples treated with F-ara-A $(F)$ or etoposide $(E)$, even at supraphysiological concentrations. (+) denotes genomic DNA. $M$ denotes the 100 bp DNA ladder. 

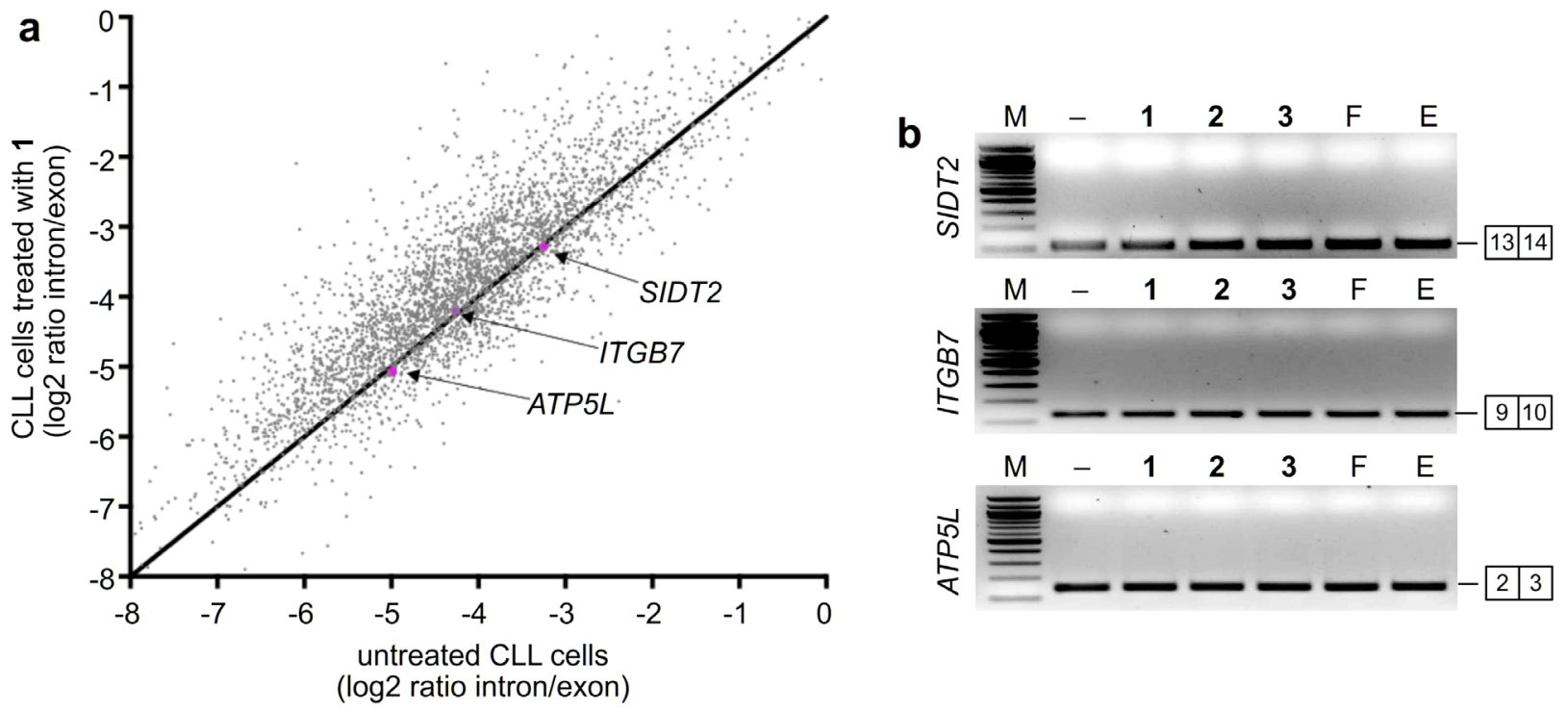

\begin{tabular}{|c|c|c|c|c|}
\hline Gene Symbol & Refseq ID & $\begin{array}{c}\text { CLL } \\
\text { (I/E) Ratio }\end{array}$ & $\begin{array}{c}\text { CLL-FD-895 } \\
\text { (I/E) Ratio }\end{array}$ & $\begin{array}{c}\text { Net Change } \\
\text { (T/U) }\end{array}$ \\
\hline$I T G B 7$ & NM_000889 & -4.256266 & -4.263966 & 1.001809097 \\
\hline SIDT2 & NM_001040455 & -3.25144 & -3.330318 & 1.024259405 \\
\hline ATP5L & NM_006476 & -4.888689 & -5.070314 & 1.037152087 \\
\hline
\end{tabular}

Supplementary Figure S3. Validation of non-spliceosomal genes for intron retention. a) We analyzed RNAseq data for CLL-B treated with $100 \mathrm{nM}$ FD895 (treated, T) versus CLL untreated $(\mathrm{U})$ to identify unchanged non-spliceosomal genes as shown in the scatter plot. We selected SIDT2, ITGB7, and ATP5L genes based on the fold change for intron retention (IR) between treated and untreated cells CLL-B cells as shown in the table (bottom). The intron retention (IR) has been presented in form of $\log 2$ ratio of FPKM intron/exon (I/E) ratio, where FPKM represents fragments per kilobase of transcript per million mapped reads. b) Alike, intron-less genes, the splice modulators $\mathbf{1}, \mathbf{2}$ and $\mathbf{3}$ do not induce IR in non-spliceosomal genes SIDT2, ITGB7 and ATP5L. The MCL-B cells were treated with either $100 \mathrm{nM} \mathrm{1,} 100 \mathrm{nM} \mathrm{2,100}$

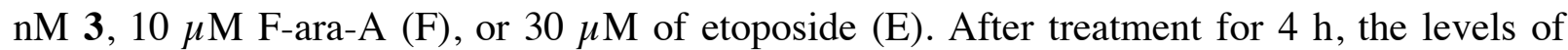
spliced versus unspliced transcripts were evaluated by RT-PCR analysis. IR was not observed in neither the treated cells nor in untreated consider as control (-) or samples treated with F-araA (F) or etoposide (E), even at supra-physiological concentrations. The (+) sign denotes genomic DNA. M denotes the 100 bp DNA ladder. 

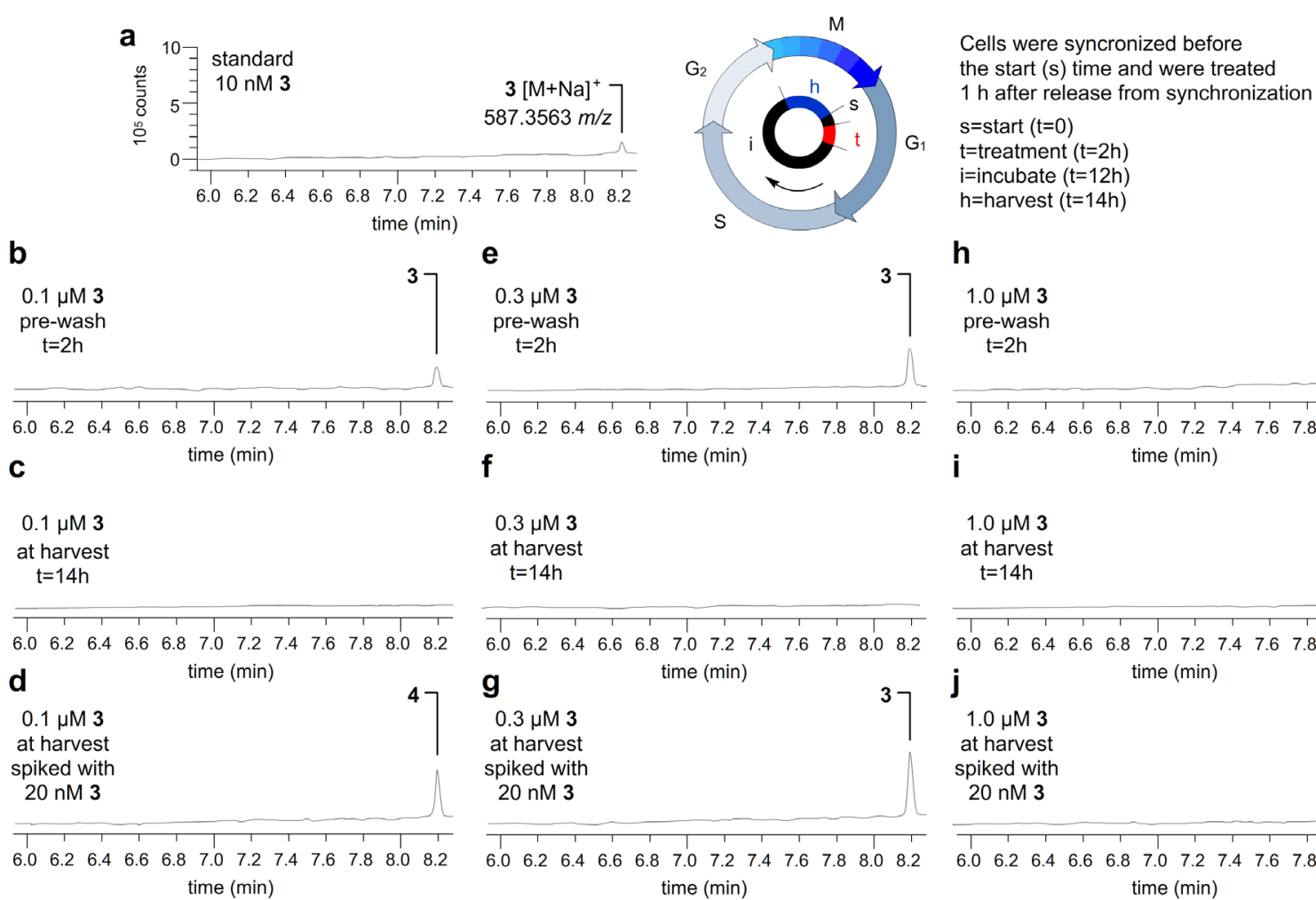

$0.3 \mu \mathrm{M} 3$

pre-wash

$t=2 h$

$1.0 \mu \mathrm{M} 3$

pre-wash

$\mathrm{t}=2 \mathrm{~h}$

$\begin{array}{llllllllllll}6.0 & 6.2 & 6.4 & 6.6 & 6.8 & 7.0 & 7.2 & 7.4 & 7.6 & 7.8 & 8.0 & 8.2\end{array}$

f

time (min)

$\begin{array}{llllllllllllllll}6.0 & 6.2 & 6.4 & 6.6 & 6.8 & 7.0 & 7.2 & 7.4 & 7.6 & 7.8 & 8.0 & 8.2\end{array}$

$0.3 \mu \mathrm{M} 3$

at harvest

$t=14 h$

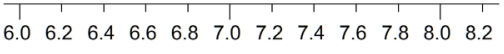

g

time ( $\mathrm{min})$

$0.3 \mu \mathrm{M} 3$
at harvest

spiked with

$20 \mathrm{nM} 3$

$6.0 \quad 62 \quad 64 \quad 66 \quad 68 \quad 70 \quad 7274476 \quad 78 \quad 8082$

time $(\min )$

$1.0 \mu \mathrm{M} 3$

at harvest

$\mathrm{t}=14 \mathrm{~h}$

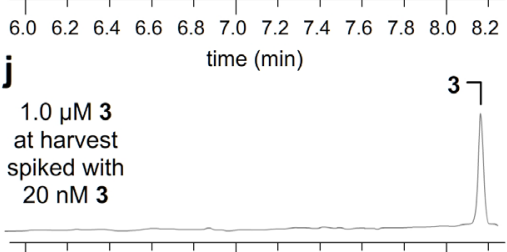

$\begin{array}{llllllllllll}6.0 & 6.2 & 6.4 & 6.6 & 6.8 & 7.0 & 7.2 & 7.4 & 7.6 & 7.8 & 8.0 & 8.2\end{array}$ time $(\mathrm{min})$

Supplementary Figure S4. Concentration of $\mathbf{3}$ in JeKo-1 cells using LC-MS analysis. Expansions of LC-HRMS traces from $6.0 \mathrm{~min}$ to $8.2 \mathrm{~min}$ depicting: a) LC-HRMS trace at the limit of detection at $0.2 \mathrm{pg}$ of $\mathbf{3}$ from injection of $20 \mu \mathrm{L}$ of a $10 \mathrm{nM} 3$ in PBS; b) An extract from JeKo-1 cells treated with $0.1 \mu \mathrm{M} 3$ for $2 \mathrm{~h}$, frozen and then extracted; c) An extract from JeKo- 1 cells treated with $0.1 \mu \mathrm{M} 3$ for $2 \mathrm{~h}$ then washed, incubated for an additional $12 \mathrm{~h}(\mathrm{t}=14$ h), frozen and then extracted; d) The extract from c) after spiking with $20 \mathrm{nM} 3$ in PBS; e) An extract from JeKo-1 cells treated with $0.3 \mu \mathrm{M} 3$ for $2 \mathrm{~h}$, frozen and then extracted; f) An extract from JeKo-1 cells treated with $0.3 \mu \mathrm{M} 3$ for $2 \mathrm{~h}$ then washed, incubated for an additional $12 \mathrm{~h}(\mathrm{t}=14 \mathrm{~h})$, frozen and then extracted; g) The extract from $\mathrm{f}$ ) after spiking with 20 $\mathrm{nM} 3$ in PBS; h) An extract from JeKo-1 cells treated with $1.0 \mu \mathrm{M} 3$ for $2 \mathrm{~h}$, frozen and then extracted; i) An extract from JeKo-1 cells treated with $1.0 \mu \mathrm{M} 3$ for $2 \mathrm{~h}$ then washed, incubated for an additional $12 \mathrm{~h}(\mathrm{t}=14 \mathrm{~h})$, frozen and then extracted; j) The extract from $\mathrm{h}$ ) after spiking with $20 \mathrm{nM} 3$ in PBS. Extracts were prepared from a pellet of cells with a wet weight of $51 \pm 8$ mg. Each run was developed from injection of $20 \mu \mathrm{L}$ of sample containing $20 \%$ of the total extract. Spiked samples were injected at $25 \mu \mathrm{L}$ with the additional $5 \mu \mathrm{L}$ of $100 \mathrm{nM} 3$ in PBS. All plots were standardized to the same intensity of counts on the y-axis as shown in a). For ease of reading, the y-axes were not shown in b)-j). Spectra were generated from the extracted ion chromatogram at mass $\mathrm{m} / \mathrm{z}$ of 587.356. All analyses were conducted in triplicate and exemplary 3 runs are provided. Standardization was used to determine the limit of the method at $0.2 \mathrm{pg}$ per injection. At this level, the limit of detection in a sample of tissue was $20 \mathrm{pg} / \mathrm{g}$ of cell pellet. 
Supplementary Table 1. List and ranking of the top genes subjected to induction of intron retention in CLL-B cells treated with FD-895 (1) as compared to untreated CLL-B cells.

\begin{tabular}{|c|c|c|c|}
\hline Rank & Gene & Symbol & Description \\
\hline 7 & 3178 & HNRNPAI & heterogeneous nuclear ribonucleoprotein A1 \\
\hline 28 & 6428 & SRSF3 & serine/arginine-rich splicing factor 3 \\
\hline 37 & 9939 & $R B M 8 A$ & RNA binding motif protein $8 \mathrm{~A}$ \\
\hline 52 & 9775 & EIF4A3 & eukaryotic translation initiation factor $4 \mathrm{~A} 3$ \\
\hline 65 & 220988 & HNRNPA3 & heterogeneous nuclear ribonucleoprotein A3 \\
\hline 90 & 27316 & $R B M X$ & RNA binding motif protein, $\mathrm{X}$-linked \\
\hline 102 & 10189 & ALYREF & Aly/REF export factor \\
\hline 168 & 2962 & GTF2F1 & general transcription factor IIF, polypeptide $1,74 \mathrm{kDa}$ \\
\hline 177 & 51340 & CRNKL1 & crooked neck pre-mRNA splicing factor-like 1 \\
\hline 180 & 6629 & SNRPB2 & small nuclear ribonucleoprotein polypeptide B \\
\hline 214 & 23210 & JMJD6 & jumonji domain containing 6 \\
\hline 220 & 10594 & PRPF8 & pre-mRNA processing factor 8 \\
\hline 239 & 6628 & SNRPB & small nuclear ribonucleoprotein polypeptides B and B1 \\
\hline 254 & 10421 & $C D 2 B P 2$ & CD2 (cytoplasmic tail) binding protein 2 \\
\hline 263 & 10291 & SF3A1 & splicing factor $3 \mathrm{a}$, subunit $1,120 \mathrm{kDa}$ \\
\hline 271 & 6421 & $S F P Q$ & splicing factor proline/glutamine-rich \\
\hline 281 & 10992 & $S F 3 B 2$ & splicing factor $3 \mathrm{~b}$, subunit $2,145 \mathrm{kDa}$ \\
\hline 300 & 8899 & PRPF4B & PRP4 pre-mRNA processing factor 4 homolog B \\
\hline 313 & 5411 & $P N N$ & pinin, desmosome associated protein \\
\hline 323 & 5936 & RBM4 & RNA binding motif protein 4 \\
\hline 324 & 5440 & POLR2K & polymerase (RNA) II (DNA directed) polypeptide K, 7.0kDa \\
\hline 356 & 51639 & SF3B14 & splicing factor $3 \mathrm{~B}, 14 \mathrm{kDa}$ subunit \\
\hline 376 & 3190 & HNRNPK & heterogeneous nuclear ribonucleoprotein $\mathrm{K}$ \\
\hline 394 & 51503 & $C W C 15$ & CWC15 spliceosome-associated protein homolog \\
\hline 396 & 27339 & PRPF19 & pre-mRNA processing factor 19 \\
\hline 415 & 708 & $C 1 Q B P$ & complement component $1, \mathrm{q}$ subcomponent binding protein \\
\hline 478 & 6634 & SNRPD3 & small nuclear ribonucleoprotein D3 polypeptide 18kDa \\
\hline 508 & 25949 & SYF2 & SYF2 homolog, RNA splicing factor \\
\hline 534 & 5725 & PTBP1 & polypyrimidine tract binding protein 1 \\
\hline 583 & 6434 & $T R A 2 B$ & transformer 2 beta homolog \\
\hline 584 & 6625 & SNRNP70 & small nuclear ribonucleoprotein 70kDa (U1) \\
\hline 607 & 8220 & DGCR14 & DiGeorge syndrome critical region gene 14 \\
\hline 620 & 56949 & $X A B 2$ & XPA binding protein 2 \\
\hline 624 & 10262 & SF3B4 & splicing factor $3 \mathrm{~b}$, subunit $4,49 \mathrm{kDa}$ \\
\hline 626 & 11218 & $D D X 20$ & DEAD (Asp-Glu-Ala-Asp) box polypeptide 20 \\
\hline 644 & 1477 & CSTF1 & cleavage stimulation factor, 3 pre-RNA, subunit $1,50 \mathrm{kDa}$ \\
\hline 681 & 11100 & HNRNPUL1 & heterogeneous nuclear ribonucleoprotein U-like 1 \\
\hline 708 & 10569 & SLU7 & SLU7 splicing factor homolog \\
\hline 720 & 3192 & $H N R N P U$ & heterogeneous nuclear ribonucleoprotein $\mathrm{U}$ \\
\hline 743 & 5435 & POLR2F & polymerase (RNA) II (DNA directed) polypeptide F \\
\hline 782 & 27258 & LSM3 & LSM3 homolog, U6 small nuclear RNA associated \\
\hline 804 & 3191 & HNRNPL & heterogeneous nuclear ribonucleoprotein L \\
\hline 862 & 9785 & DHX38 & DEAH (Asp-Glu-Ala-His) box polypeptide 38 \\
\hline 888 & 24144 & TFIP11 & tuftelin interacting protein 11 \\
\hline 898 & 6431 & SRSF6 & serine/arginine-rich splicing factor 6 \\
\hline
\end{tabular}




\begin{tabular}{|c|c|c|l|}
\hline 932 & 988 & CDC5L & cell division cycle 5-like \\
\hline 943 & 23524 & SRRM2 & serine/arginine repetitive matrix 2 \\
\hline 961 & 6632 & SNRPD1 & small nuclear ribonucleoprotein D1 polypeptide 16kDa \\
\hline 993 & 135295 & SRSF12 & serine/arginine-rich splicing factor 12 \\
\hline 1005 & 1660 & DHX9 & DEAH (Asp-Glu-Ala-His) box helicase 9 \\
\hline 1009 & 23398 & $P P W D 1$ & peptidylprolyl isomerase domain and WD repeat containing 1 \\
\hline 1010 & 10978 & $C L P 1$ & cleavage and polyadenylation factor I subunit 1 \\
\hline 1063 & 3181 & $H N R N P A 2 B 1$ & heterogeneous nuclear ribonucleoprotein A2/B1 \\
\hline 1066 & 11338 & $U 2 A F 2$ & U2 small nuclear RNA auxiliary factor 2 \\
\hline 1083 & 8175 & $S F 3 A 2$ & splicing factor 3a, subunit 2, 66kDa \\
\hline 1099 & 1659 & DHX8 & DEAH (Asp-Glu-Ala-His) box polypeptide 8 \\
\hline 1151 & 6633 & $S N R P D 2$ & small nuclear ribonucleoprotein D2 polypeptide 16.5kDa \\
\hline 1178 & 5441 & $P O L R 2 L$ & polymerase (RNA) II (DNA directed) polypeptide L, 7.6kDa \\
\hline 1262 & 5434 & $P O L R 2 E$ & polymerase (RNA) II (DNA directed) polypeptide E, 25kDa \\
\hline 1272 & 9128 & $P R P F 4$ & PRP4 pre-mRNA processing factor 4 homolog \\
\hline 1299 & 6426 & $S R S F 1$ & serine/arginine-rich splicing factor 1 \\
\hline 1334 & 10492 & $S Y N C R I P$ & synaptotagmin binding, cytoplasmic RNA interacting protein \\
\hline 1357 & 5439 & $P O L R 2 J$ & polymerase (RNA) II (DNA directed) polypeptide J, 13.3kDa \\
\hline 1386 & 84844 & $P H F 5 A$ & PHD finger protein 5A \\
\hline 1389 & 3189 & $H N R N P H 3$ & heterogeneous nuclear ribonucleoprotein H3 (2H9) \\
\hline 1411 & 2521 & $F U S$ & fused in sarcoma \\
\hline 1547 & 4670 & HNRNPM & heterogeneous nuclear ribonucleoprotein M \\
\hline 1575 & 23450 & SF3B3 & splicing factor 3b, subunit 3, 130kDa \\
\hline 1587 & 4809 & NHP2L1 & NHP2 non-histone chromosome protein 2-like 1 \\
\hline 1653 & 10250 & $S R R M 1$ & serine/arginine repetitive matrix 1 \\
\hline 1663 & 22826 & DNAJC8 & DnaJ (Hsp40) homolog, subfamily C, member 8 \\
\hline & & & \\
\hline
\end{tabular}


Supplementary Table 2. Sequences of the RT-PCR primers used in this study.

\begin{tabular}{|c|c|c|}
\hline \multicolumn{3}{|c|}{ RT-PCR primers } \\
\hline Primer & Location & 5' Sequence 3' \\
\hline DNAJA1-FP & Exon 4 & CAGCTCTCAGTAACCCTAGA \\
\hline DNAJA1-RP & Exon 5 & CTGAACCATTCCAGGTCCTAT \\
\hline DNAJB1-FP & Exon 2 & GAACCAAAATCACTTTCCCCAAGGAAGG \\
\hline DNAJB1-RP & Exon 3 & AATGAGGTCCCCACGTTTCTCGGGTGT \\
\hline$R I O K 3-\mathrm{FP}$ & Exon 3 & CCAGTGACCTTATGCTGGCTCAGAT \\
\hline RIOK3-RP & Exon 4 & GGTCTGTAGGGATCATCACGAGTA \\
\hline SF3B1-FP & Exon 14 & AAGTCCTGGCAAGCGAGACA \\
\hline SF3B1-RP & Exon 15 & TCCTCTGTGTTGGCGGATAC \\
\hline SF3B2-FP & Exon 10 & GCAGCTGATGTTGAGATTGAG \\
\hline SF3B2-RP & Exon 11 & CATCATCACTGTCCTTGTGC \\
\hline SF3B3-FP & Exon 7 & AATGACCTGGATGACCCTGA \\
\hline SF3B3-RP & Exon 8 & TAAGCACACACATGGCAGCA \\
\hline SF3B4-FP & Exon 2 & AACTGTTTCTCCAGGCTGGA \\
\hline SF3B4-RP & Exon 3 & GGCTTCCCATAGAGTTTGATC \\
\hline SF3A1-FP & Exon 6 & GGCCTATGCTCAGATCGACT \\
\hline SF3Al-RP & Exon 7 & ATCAGACTCGACCTCCATC \\
\hline SF3A3-FP & Exon 5 & TCTGTGTGCCAATGTCAGTG \\
\hline SF3A3-RP & Exon 6 & CTCAGATGCCTTCAGGTTAAT \\
\hline SRSF6-FP & Exon 5 & TTGGACAAACTGGATGGCAC \\
\hline SRSF6-RP & Exon 6 & TACTTCGAGATCTACTGCGG \\
\hline ZRSR2-FP & Exon 1 & CGCCCGAGAAGATGACGTTT \\
\hline ZRSR2-RP & Exon 2 & CTGAGTCTCTCAGTCGAGCA \\
\hline PRPF4-FP & Exon 8 & GAGTGGGCTTTGCAAGCTCT \\
\hline PRPF4-RP & Exon 9 & CTGTCGAGACTCCAAAGCTT \\
\hline PRPF4B-FP & Exon 11 & TGTCTGAGACTCTTCAGGCA \\
\hline PRPF4B-RP & Exon 12 & GGCTTGATATCTGCATGTAGG \\
\hline$A R F 4-\mathrm{FP}$ & Exon 2 & GATTGGATGCTGCTGGCAA \\
\hline ARF4-RP & Exon 3 & GATTGGATGCTGCTGGCAA \\
\hline SF1-FP & Exon 9 & GATCTTAAGACCCTGGCAGA \\
\hline SF1-RP & Exon 10 & CGGTGGAGGTGGGTTGTTGG \\
\hline$U 2 A F 2-\mathrm{FP}$ & Exon 4 & AGGTCCGTAAATACTGGGAC \\
\hline$U 2 A F 2-\mathrm{RP}$ & Exon 5 & CTCAGTGATGCCAAAGGGGA \\
\hline$M C L 1-\mathrm{FP}$ & Exon 1 & CTCGGTACCTTCGGGAGCAGGC \\
\hline$M C L 1-\mathrm{RP}$ & Exon 3 & CCAGCAGCACATTCCTGATGCC \\
\hline$G A P D H-\mathrm{FP}$ & Exon 3 & TGGTCACCAGGGCTGCTT \\
\hline$G A P D H-\mathrm{RP}$ & Exon 4 & AGCTTCCCGTTCTCAGCCTT \\
\hline$P L K-1-\mathrm{FP}$ & Exon 2 & ATTGTGCTTGGCTGCCAGTAC \\
\hline$P L K-1-\mathrm{RP}$ & Exon 3 & GATACACCCAATGGACCACAC \\
\hline$H 2 A-\mathrm{FP}$ & Intronless & ATGGCTGCGGTCCTCGAGTAT \\
\hline$H 2 A-\mathrm{RP}$ & Intronless & TCAGTTCCTCGTTGCGGA \\
\hline RNU6A-FP & Intronless & CGCTTCGGCAGCACATATAC \\
\hline$R N U 6 A-\mathrm{RP}$ & Intronless & GAATTTGCGTGTCATCCTT \\
\hline ITGB7-FP & Exon 9 & ATCGAGGACAGTGCAACCACGT \\
\hline ITGB7-RP & Exon 10 & TCAGCTCCTCTGAGAAGCCAAG \\
\hline SIDT2-FP & Exon 15 & GGATGACTACGACACATTGACCG \\
\hline SIDT2-RP & Exon 16 & TTCCGCAGAACACGCTTGTCCT \\
\hline ATP5L-FP & Exon 2 & CCTGCTGAGATCCCTAGAGCTA \\
\hline ATP5L-RP & Exon 3 & CCGACATAAAACCACATCAACACC \\
\hline & forward & mer; RP reverse primer \\
\hline
\end{tabular}


Supplementary Table 3. Sequences of the qRT-PCR primers used in this study.

\begin{tabular}{|c|c|c|}
\hline \multicolumn{3}{|c|}{ qRT-PCR primers } \\
\hline Primer & Location & 5' Sequence 3' \\
\hline DNAJA1-FP & Intron 4 & CCAACTGAAAACCTCCCACCT \\
\hline DNAJA1-RP & Intron 4 & GCCTGATGGAATGCTACCCT \\
\hline DNAJB1-FP & Intron 2 & GGCCTGATGGGTCTTATCTATGG \\
\hline DNAJB1-RP & Intron 2 & TTAGATGGAAGCTGGCTCAAGAG \\
\hline$B R D 2-\mathrm{FP}$ & Intron 2 & AGGTAATGTCACAGGATGGGAAGT \\
\hline BRD2-RP & Intron 2 & CCCTGCTGCCTTTCTCTAACC \\
\hline RIOK3 -FP & Intron 3 & CCTTATTGTGACAACTTCATTGAG \\
\hline RIOK3-RP & Intron 3 & TGAAGATTTACTTAGGAGCACA \\
\hline SF3B1-FP & Intron 13 & GGGCTACTGATTTGGGGAGA \\
\hline SF3B1-RP & Intron 13 & CATGAACCATAGCCTGTCAGC \\
\hline SF3B2-FP & Intron 10 & GGGGGACTTAAATTCCTGGGG \\
\hline SF3B2-RP & Intron 10 & CAGAGAGTGGGCAACACCAA \\
\hline SF3B3-FP & Intron 7 & GGACGAGCTCTGTGAGTTGT \\
\hline SF3B3-RP & Intron 7 & ATGGGCCAGTCATGCCAATC \\
\hline SF3B4-FP & Intron 2 & TGAGTACATGACAAGGGGCG \\
\hline SF3B4-RP & Intron 2 & TGGGGTAAAATTCATCTACCCTCT \\
\hline SF3A1-FP & Intron 6 & GGTGTTCCCAGAGAGCAGTAG \\
\hline SF3A1-RP & Intron 6 & GCTGGGGCCATGTCTGTTTT \\
\hline SF3A3-FP & Intron 5 & CAGCCATGGCCTCAGAGATA \\
\hline SF3A3-RP & Intron 5 & TTTGCCCAAGACCAACTTAGGA \\
\hline SRSF6-FP & Intron 5 & TGAGTGATGTCAATTGTTGCCTAC \\
\hline SRSF6-RP & Intron 5 & ATCCGTGCCATCTGGCAAAA \\
\hline ZRSR2-FP & Intron 1 & GGAAGAAAAGAGAAGCTGGGC \\
\hline ZRSR2-RP & Intron 1 & CAGTTCTTCTCCATCCGCCA \\
\hline PRPF4-FP & Intron 8 & TGCTTGACACTCAGACCCCA \\
\hline PRPF4-RP & Intron 8 & AAAATGCCAGAGTGTGACTGC \\
\hline PRPF4B-FP & Intron 11 & ACAGTGTGGCTTTGTTGTGTT \\
\hline$P R P F 4 B-\mathrm{RP}$ & Intron 11 & AAGAACCACCCCCACATTTGA \\
\hline$A R F 4-\mathrm{FP}$ & Intron 2 & GTAAGAAAGTTTACAGATGACTT \\
\hline ARF4-RP & Intron 2 & AGATAATCAACATGCTTAACAAA \\
\hline SF1-FP & Intron 9 & CAGTTGCAAGTCAGCACTCG \\
\hline SF1-RP & Intron 9 & CGGTGGAGGTGGGTTGTTGG \\
\hline GAPDH-FP & Exon 3 & TGGTCACCAGGGCTGCTT \\
\hline GAPDH-RP & Exon 4 & AGCTTCCCGTTCTCAGCCTT \\
\hline & forward & imer; RP reverse primer \\
\hline
\end{tabular}

